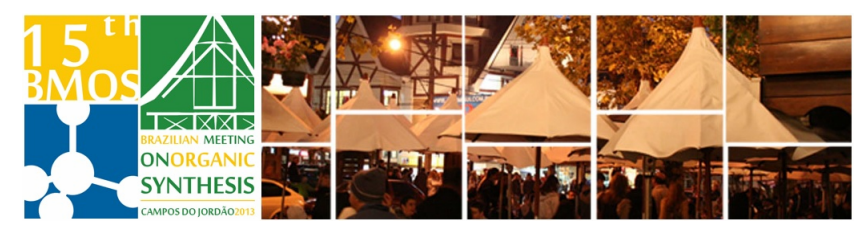

\title{
New modular structures constructed by click chemistry
}

\section{Guillermo Valdomir ${ }^{\mathrm{a}}$, José M. Padrón ${ }^{\mathrm{b}}$, Juan I. Padrón ${ }^{\mathrm{b}, \mathrm{c}}$, Víctor S. Martín ${ }^{\mathrm{b}}$, Danilo Davyt $^{\mathrm{a}^{*}}$}

aLaboratorio de Química Farmacéutica, Departamento de Química Orgánica, Facultad de Química, UdelaR, Montevideo, Uruguay. 'Instituto Universitario de Bio-Orgánica "Antonio González" (IUBO-AG), La Laguna, España. ' Instituto de Productos Naturales y Agrobiología, CSIC, La Laguna, España.

*e-mail corresponding author: ddavyt@fq.edu.uy

Keywords: Click Chemistry, Huisgen reaction, Antiproliferative activity.

\section{INTRODUCTION}

Inspired by diferent natural compounds with cytotoxic activity, we synthesised new modular compounds by Click Chemistry, ${ }^{1}$ using two kinds of building blocks which can be easily coupled. The $\mathrm{Cu}(\mathrm{I})$ catalyzed version of the Huisgen reaction, was the tool selected for the coupling of the building blocks. These compounds have been tested to determine their antiproliferative activity against five human solid tumor cell lines.

\section{RESULTS AND DISCUSSION}

During our studies of hybrid compounds, we synthesized compound 1a (Figure 1) which showed moderate antiproliferative activity.

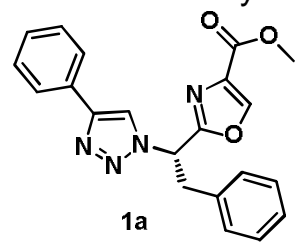

Figure 1. First cytotoxic structure obtained

In order to improve this result, we focused our efforts into the synthesis of compounds with a general structure 1 (Figure 2), based in two diferents building blocks. The first building block corresponds to an aromatic ethynyl compound, which was synthesized from aromatic aldehydes by means of Corey-Fuchs reaction. ${ }^{2}$ The second building block, corresponds to an oxazole or thiazole ring, and was synthesized from serine dipeptides. ${ }^{3}$ Using this aproach, we proposed 4 zones which can be appropiate for modifications.
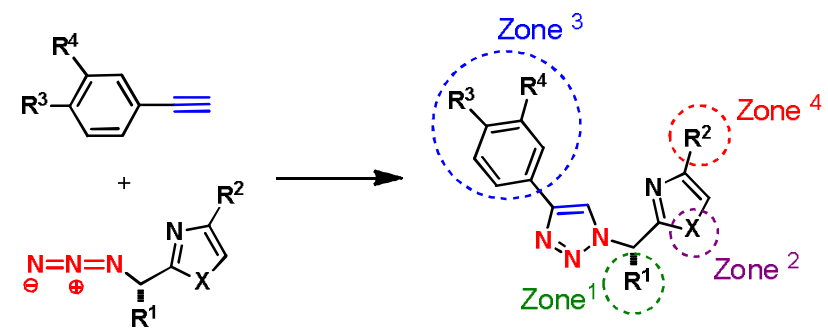

Zone 1 can be modified using diferent aminoacids as starting material. Zone 2 corresponds to the synthesis of oxazole or thiazole rings. Zone 3 can be modified changing the starting aldehyde. Zone 4 corresponds to modifications of the methyl ester of $1 a$.

This way, we synthesized 16 new compounds, and they were assayed in vitro to determine their antiproliferative activity against five human solid tumor cell lines. Only two of the new compounds showed a better profile than the parent compound. Apparently modifications of Zones 2 and 4, produce loss of activity, and Zones 1 and 3, admit only few changes.

\section{CONCLUSION}

We have developed the synthesis of new modular products, created a small library of related compounds and assayed them to determine their antiproliferative activity. Besides only two of the new compouns show activity, we think that it's still possible to improve the activities obtained so far, with new compounds.

\section{ACKNOWLEDGEMENTS}

This work was financialy supported by CSIC grupos; G.V. would like to thanks ANII (Agencia Nacional de Investigación e Innovación) for a doctoral fellowship BE_POS_2010_1_2422.

\section{REFERENCES}

${ }^{1}$ Kolb, H. C.; Finn, M. G.; Sharpless, K. B. Angew. Chem. Int. Ed. 2001, 40, 2004.

${ }^{2}$ Fuchs, P. L.; Corey, E. J. Tetrahedron Lett. 1972, 13, 3769

${ }^{3}$ Phillips, A. J.; Uto, Y.; Wipf, P.; Reno, M. J.; Williams, D. R. Org. Lett. 2000, 2, 1165.

Figure 2. Synthesis of related compounds

$15^{\text {th }}$ Brazilian Meeting on Organic Synthesis $-15^{\text {th }}$ BMOS - November 10-13, 2013 - Campos do Jordão, Brazil 